\title{
Chronic peritoneal dialysis in Chinese infants and children younger than two years
}

\author{
YH Chan *, Alison LT Ma, PC Tong, WM Lai, Niko KC Tse
}

\section{A B S T R A C T}

Objective: To review the outcome for Chinese infants and young children on chronic peritoneal dialysis.

Methods: The Paediatric Nephrology Centre of Princess Margaret Hospital is the designated site offering chronic dialysis to children in Hong Kong. Medical records of children who started chronic peritoneal dialysis before the age of 2 years, from 1 July 1995 to 31 December 2013, were retrieved and retrospectively reviewed.

Results: Nine Chinese patients (male-to-female ratio, 3:6) were identified. They were commenced on automated peritoneal dialysis at a median age of 4.7 (interquartile range, 1.1-13.3) months. The median duration of chronic peritoneal dialysis was 40.9 (interquartile range, 22.9-76.2) months. The underlying aetiologies were renal dysplasia $(n=3)$, pneumococcal-associated haemolytic uraemic syndrome $(n=3)$, ischaemic nephropathy $(n=2)$, and primary hyperoxaluria $I(n=1)$. Peritonitis and exit-site infection rate was 1 episode per 46.5 patient-months and 1 episode per 28.6 patient-months, respectively. Dialysis adequacy $\left(\mathrm{Kt} / \mathrm{V}_{\text {urea }}>1.8\right)$ was achieved in $87.5 \%$ of patients. Weight gain was achieved in our patients although three required gastrostomy. Four patients

This article was published on 17 Jun 2016 at www.hkmj.org. were delayed in development. All patients survived except one patient with primary hyperoxaluria I who died of acute portal vein thrombosis following liver transplantation. One patient with pneumococcalassociated haemolytic uraemic syndrome had sufficient renal function to be weaned off dialysis. Four patients received deceased donor renal transplantation after a mean waiting time of 76.7 months. Three patients remained on chronic peritoneal dialysis at the end of the study.

Conclusions: Chronic peritoneal dialysis is technically difficult in infants. Nonetheless, low peritonitis rate, low exit-site infection rate, and no chronic peritoneal dialysis-related mortality can be achieved. Chronic peritoneal dialysis offers a promising strategy to bridge the way to renal transplantation.

\section{Hong Kong Med J 2016;22:365-71 DOI: $10.12809 / \mathrm{hkmj} 154781$ \\ YH Chan *, FHKCPaed, FHKAM (Paediatrics) \\ ALT Ma, FHKCPaed, FHKAM (Paediatrics) \\ PC Tong, FHKCPaed, FHKAM (Paediatrics) \\ WM Lai, FHKCPaed, FHKAM (Paediatrics) \\ NKC Tse, FHKCPaed, FHKAM (Paediatrics)}

Paediatric Nephrology Centre, Department of Paediatric and Adolescent Medicine, Princess Margaret Hospital, Laichikok, Hong Kong

* Corresponding author: genegene.chan@gmail.com

New knowledge added by this stud

- Literature on infant chronic peritoneal dialysis (CPD) is scarce. This is the first report about long-term outcome of Chinese infants on CPD.

- The local catheter-related infection rate is low compared with western countries.

Implications for clinical practice or policy

- $\mathrm{CPD}$ in infancy is a feasible modality as a bridge to transplantation with low infection and mortality rate. A shared decision-making process between parents and paediatric nephrologists is necessary to provide an optimal care plan for this group of patients, considering the predicted outcome, associated co-morbidities, and family burden.

\section{Introduction}

End-stage renal disease (ESRD) is a rare disease with high mortality in infants and young children under 2 years of age. In the past, the decision to initiate infant dialysis was not easy due to technical difficulties and poor clinical outcome, as evidenced by a 1990 survey showing that only $50 \%$ of paediatric nephrologists would offer dialysis to ESRD children younger than 1 year, and only $40 \%$ would offer dialysis to neonates. ${ }^{1}$ With technological advances and improving outcome for children on dialysis in terms of physical growth, development and quality of life, ${ }^{2,3}$ most paediatric nephrologists will now consider peritoneal dialysis (PD) as a bridge to renal transplantation. Data in North American Pediatric Renal Trials and Collaborative Studies (NAPRTCS) 2011 indicated that $92 \%$ of ESRD children younger than 2 years were on chronic PD (CPD). ${ }^{4}$

Literature in this area is scarce $\mathrm{e}^{2,3,5,6}$ especially on the long-term outcome of these infants in the 


\section{替兩歲以下華籍嬰幼兒進行慢性腹膜透析}

\section{陳宇軒、馬立德、湯伯朝、賴偉明、謝紀超}

目的：分析華籍嬰幼兒接受慢性腹膜透析的治療結果。

方法：瑪嘉烈醫院的兒童腎臟中心是香港唯一一間為兒童提供慢性透 析治療的機構。研究透過檢索1995年7月1日至2013年12月31日期間 到上述中心接受慢性腹膜透析的兩歲以下嬰幼兒的病歷紀錄進行回顧 性分析。

結果：9名華籍嬰幼兒 (3男6女) 被納入研究範圍。他們於中位數 4.7 個月大時（四分位數間距：1.1-13.3個月）開始接受自動腹膜透析。 進行腹膜透析的時間中位數為40.9個月（四分位數間距：22.9-76.2個 月）。引致腎衰竭的原因為腎發育不良（3例）、因肺炎鍊球菌引致 溶血性尿毒症綜合症（pHUS；3例）、缺血性腎病（2例）和原發性 高草酸尿症類一型（PH1；1例）。腹膜炎和導管出口感染的比率分 別為每 46.5 病人月一次和每 28.6 病人月一次。 $87.5 \%$ 的患者能達至透 析充分（即 $\mathrm{Kt} / \mathrm{V}$ 值 $>1.8$ ）。嬰幼兒在透析期間體重逐漸增加, 當中三 人須經胃喉提供營養。四名病人發展遲緩。除了一名患有PH1的小童 在肝移植手術後死於急性門靜脈栓塞, 其他患者全部存活。一名患有 pHUS的嬰幼兒因腎功能復原母須進行腹部透析。四名兒童平均等候 76.7 個月後接受屍腎移植。三名病人在研究結束時仍須接受慢性腹膜 透析。

結論：替嬰幼兒進行慢性腹膜透析雖然困難, 但腹膜炎、導管出口感 染和與慢性腹膜透析有關而死亡的比率仍可減至最低。慢性腹膜透析 是為嬰幼兒過渡至腎移植的理想治療方案。

Chinese population. As the only tertiary referral paediatric nephrology centre in Hong Kong, we retrospectively reviewed our experience in the epidemiology, dialysis prescription, complications, and outcome in this group of patients.

\section{Methods}

The Paediatric Nephrology Centre of Princess Margaret Hospital is the designated site offering renal replacement therapy to children in Hong Kong. Medical records of children who started CPD before 2 years old, from 1 July 1995 to 31 December 2013, were retrieved and reviewed. Information regarding their primary renal diagnosis, co-morbidities, growth profile, infectious and non-infectious complications, dialysis prescription, dialysis adequacy, peritoneal membrane transport status, relevant laboratory investigations, and final outcome were reviewed. Data collected were recorded on data entry forms. Patients who underwent CPD for less than 6 months were excluded. The study was approved by the ethics committee of Princess Margaret Hospital.

In our centre, CPD was the preferred dialysis modality in young children; PD was performed by automated cycler in the modes of nocturnal intermittent peritoneal dialysis (NIPD), continuous cyclic peritoneal dialysis (CCPD), continuous optimal peritoneal dialysis, and tidal peritoneal dialysis. Peritoneal equilibration test was performed annually with membrane transport status classified as high, high-average, low-average, or low transporters. ${ }^{7,8}$ Dialysis adequacy was monitored by both clinical parameters and biochemical parameters. Due to limited information on residual renal function, solute clearance referred to contribution by CPD only, and was expressed in terms of $\mathrm{Kt} / \mathrm{V}_{\text {urea }}$.

Peritonitis was defined as cloudy peritoneal effluent, with white cell count of $>100 / \mathrm{mm}^{3}$ in the dialysate with at least $50 \%$ polymorphonuclear leukocytes. ${ }^{9}$ Additionally, clinical symptoms of fever with or without abdominal pain were included. Exitsite infection (ESI) was diagnosed in the presence of peri-catheter swelling, redness, tenderness, and discharge at the exit site. ${ }^{9}$ Developmental delay was defined as children who received special education or failed to reach a normal developmental milestone in two or more developmental domains (eg gross motor, cognition, etc).

Chronic kidney disease-mineral bone disease (CKD-MBD) was defined as a systemic disorder of mineral bone metabolism due to renal failure, manifesting as biochemical abnormalities (calcium, phosphate, parathyroid hormone [PTH], or vitamin D metabolism), abnormal bone turnover, or vascular calcification. ${ }^{10}$ Renal osteodystrophy, the skeletal component of CKD-MBD, was defined as alteration of bone morphology in patients with ESRD. ${ }^{10}$ Target of PTH ranged from 11 to $33 \mathrm{pmol} / \mathrm{L}(100-300 \mathrm{pg} / \mathrm{mL})$ in children on CPD, supported by recent data from the International Pediatric Peritoneal Dialysis Network (IPDN). ${ }^{11}$

\section{Statistical analysis}

Data collection and analysis were performed with Microsoft Excel 2010. The demographic data and biochemical parameters were expressed as mean \pm standard deviation, range, median, interquartile range (IQR), number, or percentage as appropriate. Height and weight were expressed as standard deviation scores (SDSs), calculated according to a local study on growth of children. ${ }^{12}$

\section{Results}

\section{Patient characteristics}

From 1995 to 2013, nine Chinese children under 2 years of age ( 3 boys and 6 girls) receiving CPD were identified. The mean estimated glomerular filtration rate immediately prior to dialysis was 6.9 \pm 3.8 (range, $3.9-15$ ) $\mathrm{mL} / \mathrm{min} / 1.73 \mathrm{~m}^{2}$, calculated by Schwartz Formula. The median age at initiating CPD was 4.7 (IQR, 1.1-13.3) months. The median duration of CPD was 40.9 (IQR, 22.9-76.2) months. The most common causes of ESRD were renal dysplasia $(n=3$, 33\%) and pneumococcal-associated haemolytic uraemic syndrome (pHUS) [n=3,33\%], followed by ischaemic nephropathy due to severe perinatal 
asphyxia $(\mathrm{n}=2,22 \%)$ and primary hyperoxaluria I (PH1) $[n=1,11 \%]$ (Tables 1 and 2). All three patients with pHUS presented with pneumococcal pneumonia, microangiopathic haemolytic anaemia, and acute kidney injury. Either direct Coombs test or $\mathrm{T}$-antigen test was positive to support the diagnosis of pHUS.

\section{Peritoneal dialysis prescription, transporter status, and peritoneal dialysis adequacy}

All patients were put on automated peritoneal dialysis (APD). Initially, eight children were on NIPD and only one was on CCPD. Over the course of CPD, five (56\%) patients changed to CCPD, and one (11\%) patient changed to tidal PD because of drainage pain. Three (33\%) patients remained on NIPD. Decreasing residual renal function and inadequate dialysis were the most common reasons for changing modes of CPD.

Peritoneal equilibration test and dialysis adequacy assessment were performed in eight patients. Four patients were high transporters, while two patients were high-average transporters and two patients were low-average transporters (Table 3). Seven $(87.5 \%)$ patients achieved a dialysis adequacy $\left(\mathrm{Kt} / \mathrm{V}_{\text {urea }}\right)$ of $>1.8$. The mean $\mathrm{Kt} / \mathrm{V}_{\text {urea }}$ was $2.5 \pm 0.6$ (range, 1.5-3.4). The mean weekly creatinine clearance was $38.3 \pm 6.2$ (range, 25.6-47.1) L/week/1.73 $\mathrm{m}^{2}$.

TABLE I. Summary of children younger than 2 years who were on chronic peritoneal dialysis during July 1995 to December 2013

\begin{tabular}{lc}
\hline & Data \\
\hline No. of patients enrolled & 9 \\
$\quad$ Male & 3 \\
$\quad$ Female & 6 \\
Median (IQR) age of CPD initiation (months) & $4.7(1.1-13.3)$ \\
Median (IQR) CPD duration (months) & $40.9(22.9-76.2)$ \\
Median (IQR) catheter survival (days) & $260(19-569)$ \\
Peritonitis rate & 1 Episode per 46.5 patient-months (0.26 episodes per patient-year) \\
Exit-site infection rate & 1 Episode per 28.6 patient-months (0.42 episodes per patient-year) \\
Survival rate & $8 / 9(88.9 \%)^{\star}$ \\
Dialysis adequacy (Kt/M) $\dagger$ & $2.5 \pm 0.6(1.5-3.4) \ddagger$ \\
\hline
\end{tabular}

Abbreviations: CPD = chronic peritoneal dialysis; $I Q R=$ interquartile range

* The only mortality resulted from acute portal vein thrombosis after liver transplantation, which is unrelated to CPD

† Seven (87.5\%) patients achieved a dialysis adequacy of $>1.8$

$\neq$ Mean \pm standard deviation (range)

TABLE 2. Clinical characteristics of nine Chinese children started on chronic peritoneal dialysis before 2 years old during July I 995 to December 20 I 3

\begin{tabular}{|c|c|c|c|c|c|c|c|c|c|c|c|c|c|}
\hline $\begin{array}{l}\text { Pa- } \\
\text { tient } \\
\text { No. }\end{array}$ & Sex & Diagnosis & $\begin{array}{l}\text { Comor- } \\
\text { bidities }\end{array}$ & $\begin{array}{l}\text { Delay in } \\
\text { develop- } \\
\text { ment }\end{array}$ & $\begin{array}{l}\text { Feeding } \\
\text { method }\end{array}$ & $\mathbf{G H}^{*}$ & $\begin{array}{c}\text { Year of } \\
\text { CPD } \\
\text { initiation }\end{array}$ & $\begin{array}{c}\text { CPD- } \\
\text { onset age } \\
\text { (months) }\end{array}$ & $\begin{array}{c}\text { CPD } \\
\text { duration } \\
\text { (months) }\end{array}$ & $\begin{array}{l}\text { Peri- } \\
\text { tonitis }\end{array}$ & ESI & $\begin{array}{c}\text { Severe } \\
\text { ROD† }\end{array}$ & Outcome \\
\hline 1 & $\mathrm{~F}$ & Renal dysplasia & Nil & No & Oral & Yes & 1995 & 10.10 & 40.9 & 2 & 0 & Yes & $\mathrm{HD} \rightarrow \mathrm{Tx} \neq$ \\
\hline 2 & $\mathrm{~F}$ & Renal dysplasia & Nil & No & $N G \rightarrow G \S$ & Yes & 2000 & 0.10 & 54.4 & 1 & 1 & No & Tx $\ddagger$ \\
\hline 3 & M & pHUS & Nil & No & Oral & No & 2003 & 24.00 & 90.8 & 3 & 7 & No & Tx $\ddagger$ \\
\hline 4 & $\mathrm{~F}$ & Ischaemic nephropathy & HIE, CP & Yes & Oral & Yes & 2003 & 1.30 & 76.2 & 0 & 2 & Yes & $\mathrm{HD} \rightarrow \mathrm{Tx} \neq$ \\
\hline 5 & $\mathrm{~F}$ & pHUS & Nil & No & Oral & No & 2005 & 13.26 & 8.6 & 0 & 1 & No & Recovery \\
\hline 6 & $\mathrm{~F}$ & $\mathrm{PH} 1$ & Liver failure & Yes & $\mathrm{NG} \rightarrow \mathrm{G} \S$ & No & 2008 & 4.66 & 80.7 & 0 & 0 & Yes & Death\| \\
\hline 7 & $\mathrm{~F}$ & Renal dysplasia & Prematurity & Yes & $\mathrm{NG} \rightarrow \mathrm{G} \S$ & No & 2011 & 0.93 & 25.1 & 1 & 0 & Yes & PD \\
\hline 8 & M & pHUS & $\mathrm{CP}$ & No & Oral & No & 2011 & 20.20 & 35.0 & 1 & 0 & No & PD \\
\hline 9 & M & Ischaemic nephropathy & HIE & Yes & Oralף & No & 2012 & 4.60 & 20.6 & 0 & 2 & Yes & PD \\
\hline
\end{tabular}

Abbreviations: CP = cerebral palsy; CPD = chronic peritoneal dialysis; $\mathrm{ESI}=$ exit-site infection; $\mathrm{GH}=$ growth hormone; $\mathrm{HD}=$ haemodialysis; $\mathrm{HIE}=$ hypoxic ischaemic encephalopathy; $\mathrm{PD}=$ peritoneal dialysis; $\mathrm{pHUS}=$ pneumococcal-associated haemolytic uraemic syndrome; $\mathrm{PHI}=$ primary hyperoxaluria I:

$\mathrm{ROD}=$ renal osteodystrophy; $\mathrm{T} \times \mathbf{x}=$ renal transplantation

* Growth hormone therapy before 2 years old

+ ROD with clinical or radiological manifestations

$\ddagger$ Deceased donor renal transplantation

S Switching from nasogastric (NG) tube feeding to gastrostomy (G) feeding

॥ Due to acute portal vein thrombosis after liver transplantation for $\mathrm{PHI}$

II Awaiting gastrostomy insertion 


\section{Catheter survival}

During the study period, 23 episodes of Tenckhoff catheter insertion were carried out in these nine patients. The median catheter survival was 260 (IQR, 19-569) days. Only one patient did not require any catheter change. Fourteen catheter changes were performed in eight patients. Catheters were replaced once in four patients, twice in three patients, and 4 times in one patient. The most common reason

TABLE 3. Transporter status in children younger than 2 years on chronic peritoneal dialysis*

\begin{tabular}{lc}
\hline Transporter status & No. (\%) of patients \\
\hline High & $4(50)$ \\
High-average & $2(25)$ \\
Low-average & $2(25)$ \\
Low & 0 \\
\hline
\end{tabular}

* Peritoneal equilibration test performed in 8 patients

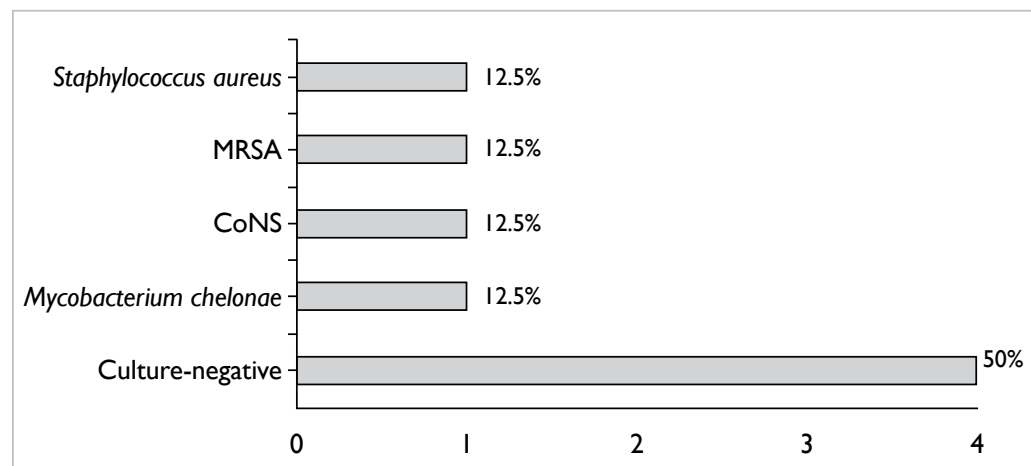

FIG I. Causative organisms in eight peritonitis episodes (five patients) in the study population

Abbreviations: CoNS = coagulase-negative Staphylococcus; MRSA = methicillinresistant Staphylococcus aureus

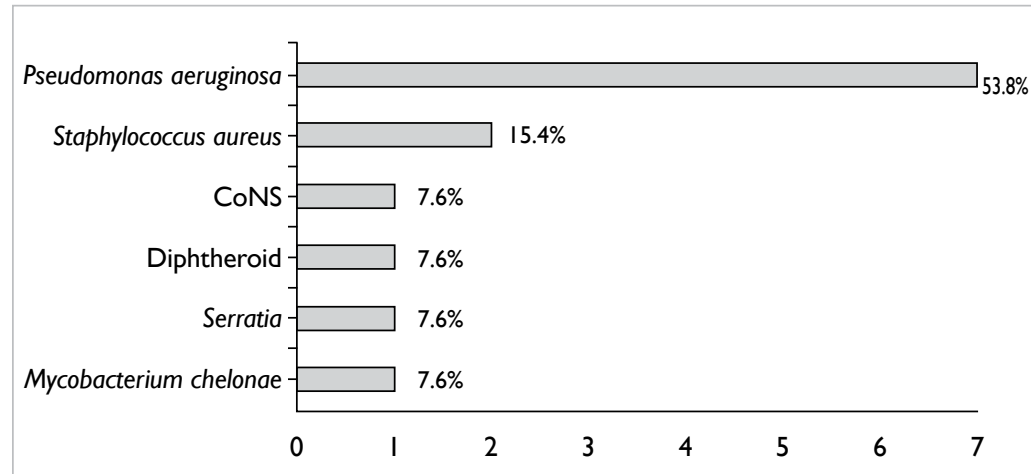

FIG 2. Causative organisms in 13 exit-site infections (five patients) in the study population

Abbreviation: CoNS = coagulase-negative Staphylococcus for catheter change was catheter blockage due to omental wrap $(n=7,50 \%)$, followed by chronic ESI or refractory peritonitis $(n=4,29 \%)$, migration or malposition ( $\mathrm{n}=2,14 \%)$, and cuff extrusion $(n=1,7 \%)$. While omentectomy was not routinely performed, $44 \%$ patients eventually required partial omentectomy due to omental wrap.

\section{Peritonitis, exit-site infection, and surgical complications}

Five patients experienced a total of eight episodes of peritonitis. Four patients did not have peritonitis. Peritonitis rate was 0.26 episode per patient-year or 1 episode per 46.5 patient-months. Two (25\%) episodes were caused by Staphylococcus aureus, one of which was methicillin-resistant. One (12.5\%) episode was caused by coagulase-negative Staphylococcus (CoNS) and the other by Mycobacterium chelonae (12.5\%). The remaining four (50\%) episodes were culture-negative peritonitis (Fig 1). Altogether 13 episodes of ESI occurred in five patients, and patient 3 contributed seven episodes. The rate of ESI was 0.42 episode per patient-year or 1 episode per 28.6 patient-months. The most common organisms were Pseudomonas aeruginosa $(\mathrm{n}=7,54 \%)$ and methicillin-sensitive $S$ aureus ( $\mathrm{n}=2,15 \%)$. Other causative pathogens included CoNS, diphtheroid, Serratia, and $M$ chelonae, each of which resulted in one ESI (Fig 2).

One patient required surgical correction of patent processus vaginalis that led to hydrocoele. One patient required repair of bilateral inguinal hernia. One patient had cuff extrusion and required replacement of PD catheter. No catheters developed leakage.

\section{Growth and nutrition}

Weight gain was observed after initiation of CPD. At the start of dialysis, 12 months and 24 months post-dialysis, the mean weight SDS (wtSDS) was $-1.32,-1.44$, and -1.27 , while height SDS (htSDS) was $-0.75,-0.92$, and -1.45 , respectively (Table 4 ). Three (33\%) patients were commenced on nasogastric (NG) enteral feeding and eventually were switched to gastrostomy feeding. Six (67\%) patients were fed on demand, one of whom was awaiting gastrostomy insertion at the end of the study. Three (33\%) patients were prescribed growth hormone therapy before the age of 2 years.

\section{Development}

Four (44\%) children were delayed in development or received special education. Two of them had severe perinatal asphyxia associated with hypoxic ischaemic encephalopathy, one was born prematurely at 32 weeks of gestation and the other had PH1, all of which could account for the developmental delay. 
TABLE 4. Growth outcome in children younger than 2 years on chronic peritoneal dialysis

\begin{tabular}{lccc}
\hline & At dialysis & $\begin{array}{c}\text { 12-Month } \\
\text { post-dialysis }\end{array}$ & $\begin{array}{c}\text { 24-Month } \\
\text { post-dialysis }\end{array}$ \\
\hline Mean height SDS & -0.75 & -0.92 & -1.45 \\
Mean weight SDS & -1.32 & -1.44 & -1.27 \\
\hline
\end{tabular}

Abbreviation: SDS = standard deviation score

\section{Anaemia, chronic kidney disease-mineral bone disease, and hypertension}

During the first 2 years of CPD, all patients received erythropoiesis-stimulating agent, except patient 5 who later became dialysis-free. The mean maximum dose of recombinant human erythropoietin ( $\mathrm{rHuEPO}$ ) was $169 \pm 91$ (range, 65-300) units $/ \mathrm{kg} /$ week. Three patients received $\mathrm{rHuEPO}$ at a dose exceeding 200 units $/ \mathrm{kg} /$ week. Seven patients were put on oral iron supplements; one of whom was switched to intravenous iron replacement subsequently due to functional iron deficiency. The mean haemoglobin level was $109 \pm 8 \mathrm{~g} / \mathrm{L}$; only two patients (patients 1 and 7) failed to achieve a mean haemoglobin level of $\geq 100 \mathrm{~g} / \mathrm{L}$.

All patients showed some degree of CKDMBD, as evidenced by raised PTH level and the need for activated vitamin $\mathrm{D}$ and phosphate binder. Five patients had severe renal osteodystrophy with clinical or radiological manifestations (Table 2). All of them had markedly elevated mean PTH (90-111 pmol/L) outside the recommended target. Of note, two patients (patients 6 and 7) had pathological fractures. Two patients (patients 7 and 9) received a calcimimetic (cinacalcet) for tertiary hyperparathyroidism. Five (56\%) patients had hypertension and were on antihypertensive medications with satisfactory control.

\section{Outcome}

All patients survived except patient 6 with PH1 who died of acute portal vein thrombosis following liver transplantation at the age of 5 years. Patient 5 with pHUS became dialysis-free after 8.6 months of CPD. Four patients underwent deceased donor renal transplantation (DDRT) with a mean waiting time of 76.7 (range, 54-90) months, of whom two were switched to chronic haemodialysis before transplantation because of inadequate dialysis. Three patients remained on PD at the end of the study.

\section{Discussion}

End-stage renal disease is rare in infants and young children. The reported incidence is variable but remains low around the globe. Up to 16 cases per age-related population per year have been reported in the UK..$^{13}$ In NAPRTCS 2011, 13.2\% of children on dialysis were under 2 years old. ${ }^{4}$ In Hong Kong, recent data from the Hong Kong Renal Registry showed that the incidence and prevalence of ESRD in those $<20$ years old was around 5 and 28 per million children, respectively. ${ }^{14}$

The most common aetiology of ESRD in this age-group is congenital anomalies of the kidney and urinary tract, including renal dysplasia and obstructive uropathy. ${ }^{15}$ Nonetheless, pHUS constituted an important cause of ESRD in Hong Kong. A potential explanation is the late introduction of a universal pneumococcal vaccination programme in 2009, compared with 2000 in the US population.

In our study, all patients started with CPD. Difficult vascular access for haemodialysis and a high volume of daily milk intake make CPD the more favourable choice of renal replacement therapy in young infants. While local mean DDRT waiting time in children younger than 18 years was $4.4 \pm$ 2.4 years ${ }^{16}$ the waiting time in our young patients was much longer (mean, 6.4 years). This is because patients have to weigh more than $15 \mathrm{~kg}$ before DDRT can be carried out due to technical difficulties. Therefore, CPD acts as a bridge to transplantation and reserves vascular access for future use. ${ }^{15}$

Ethical considerations and infection, together with growth and nutrition, are the most challenging aspects of infant CPD.

\section{Ethical considerations}

Decisions to initiate or withhold dialysis remain one of the most challenging aspects in infant ESRD. Recent data, which showed improvement in mortality and developmental outcome, support initiation of dialysis. Shroff et $\mathrm{al}^{6}$ reported a survival rate of $77 \%$ at 5 years in children commenced on chronic dialysis before the age of 1 year. Our unpublished data revealed 91 patients were put on APD from 1996 to 2013. The overall survival rate was $90 \%$. In this series, survival rate in young infants was similar and there was no CPD-related mortality. The only mortality resulted from surgical complications after liver transplantation.

Warady et $\mathrm{al}^{17}$ reported the $79 \%$ infants who started CPD had normal developmental scores at 1 and 4 years old and $94 \%$ of school-aged children attended school. In our series, $44 \%$ of patients were delayed in development, all of which could be accounted for by co-morbidities or underlying aetiology of ESRD.

Nonetheless, unpredictable outcome, psychosocial burdens, and cost continually fuel the ethical dilemma. ${ }^{13,15,18}$ The family burden is tremendous. Since CPD is a home-based treatment, caregivers must perform dialysis daily. Up to $55 \%$ of paediatric nephrologists felt a parental decision to refuse dialysis should be respected for neonates and $26 \%$ for children of 1 to 12 months old. ${ }^{13}$ In 
two surveys, serious co-existing co-morbidities and predicted morbidity were the most important factors when a physician considered withholding dialysis.,19 While serious non-renal co-morbidities such as pulmonary hypoplasia are strongly associated with a poor prognosis, ${ }^{20}$ patients with isolated renal disease should be considered separately as their prognosis is generally better. ${ }^{18}$ It should be a shared decision-making process between parents and paediatric nephrologists, after detailed counselling on potential burdens and after considering comorbidities, expected quality of life, and available resources and expertise. ${ }^{18,21}$ Designated nurses, clinical psychologists, and medical social workers are crucial in supporting patients and parents.

\section{Peritoneal dialysis-related infection}

Infants and young children are at risk of PD-related infectious complications. In the US, the annualised rate of peritonitis in children younger than 2 years was 0.79 episode per patient-year, compared with 0.57 episode per patient-year in adolescents aged over 12 years. ${ }^{4}$ In our current series, the annual peritonitis rate was 0.26 , which is less frequent than the US data. As previously reported, the overall annual peritonitis rate among all our paediatric patients on APD was low at $0.22 .{ }^{22} \mathrm{~A}$ low infection rate has similarly been reported in several Asian countries. ${ }^{22}$

There are a few possible explanations. First, all our patients were on APD that is associated with a reduced risk of infection as shown in a systematic review by Rabindranath et $\mathrm{al}^{23}$ and previous data in NAPRTCS $2005 .{ }^{24}$ Second, we strictly complied with the guidelines and recommendations on prevention of PD-related infection. ${ }^{4,9,21,25,26}$ Measures included the use of double-cuffed Tenckhoff catheters, downward or laterally pointing exit sites away from diaper and ostomies, antibiotic prophylaxis at catheter insertion, post-insertion immobilisation of the catheter, nasal methicillin-resistant $S$ aureus screening and decolonisation with mupirocin, and selective use of prophylactic topical antibiotics for patients with a history of ESI. Third, all patients and their carers completed an intensive PD training programme before commencing home APD. Training was conducted by a senior renal nurse with regular reviews and phone follow-ups. The high culture-negative peritonitis rate in our series highlights the need for proper specimen collection and handling. ${ }^{9}$

\section{Growth and nutrition}

Growth in infancy is important because one third of postnatal height is achieved during the first 2 years of life..$^{27}$ Growth during this period largely relies on nutritional intake, rather than growth hormone. Growth in ESRD is often impaired because of poor appetite, increased circulatory leptin, nutritional loss through peritoneal dialysate and repeated vomiting due to dysmotility, gastroesophageal reflux, and raised intraperitoneal pressure. ${ }^{15,27}$ Infants can lose more than 2 htSDS that can be irreversible. ${ }^{15}$ Importantly, it is also a period of catch-up growth; NAPRTCS reported improvement in both htSDS and wtSDS in children who started dialysis before the age of 2 years-htSDS improved from -2.59 at baseline to -2.15 at 24 months post-dialysis, while wtSDS improved from -2.26 to $-1.05{ }^{4}$

In our cohort, there was weight gain, but a decline in htSDS was observed. The IPDN recently analysed growth in 153 very young children on CPD. ${ }^{27}$ Interestingly, htSDS decreased further in the first 6 to 12 months of CPD and then stabilised. Although catch-up in height was noted in the NAPRTCS report, such improvement was only observed in children with worse baseline height deficit, defined as htSDS $\leq-1.88$. Children with htSDS $>-1.88$ instead had a decline in htSDS by 0.11 and 0.2 at 12 and 24 months, respectively. ${ }^{4}$ Only two of our patients had worse baseline height deficit $(\leq-1.88)$, with htSDS being -2 at CPD initiation. Similar to the findings in IPDN and NAPRTCS, catch-up growth in height was observed in these two patients. At 12 months post-dialysis, their htSDS improved to -0.94 and -1.6, respectively.

Oral intake is often unsatisfactory and enteral feeding is required, either by NG or gastrostomy tube. This allows overnight feeding and reduces vomiting. In the recent IPDN study on growth, 37\% young children were fed on demand, $39 \%$ by NG tube, $7 \%$ by gastrostomy tube, and $17 \%$ switched from NG to gastrostomy feeding. ${ }^{27}$ Both NG and gastrostomy feeding led to significant increase in body mass index SDS, although regional variation was observed. Gastrostomy but not NG feeding was associated with improved linear growth, an effect that was no longer significant after adjusting the baseline length. Feeding by gastrostomy appeared to be superior to NG tube in growth promotion and may be related to less vomiting. ${ }^{27}$

Over the years, the use of a gastrostomy to enhance nutritional supplementation has been promoted in our centre, with intensified collaboration with a paediatric renal dietitian. In our series, only one (20\%) patient who commenced CPD before 2008 received enteral feeding, owing to low parental acceptance. Of the remaining four patients who started CPD after 2008, two had gastrostomies, one was awaiting gastrostomy insertion, and one thrived satisfactorily without the need for enteral feeding. This suggests an improved nutritional management and parental acceptance. Extra efforts should also be made to optimise factors such as acidosis, anaemia, and metabolic bone disease. ${ }^{27}$ In addition, KDOQI (Kidney Disease Outcomes 
Quality Initiative) suggests consideration of growth hormone when children have htSDS and height velocity SDS of $\leq-1.88$ after optimising nutrition and metabolic abnormalities. ${ }^{28}$

There are a few limitations to this study. First, because of the retrospective study design, there was recall bias. Some information could not be retrieved from medical records, especially for children who presented in the late 1990 s and early 2000s. Second, the total case number was small since patients were recruited from a single nephrology centre. Last, infant dialysis has changed considerably over the past two decades and might in turn affect patient outcome.

\section{Conclusions}

End-stage renal disease in very young children is uncommon. Chronic PD is feasible and the outcome is improving. Vigilant adoption of guidelines, universal use of APD, and a well-structured PD training programme are crucial to achieve low peritonitis and ESI rates with no CPD-related mortality in our centre. Optimisation of dialysis, nutritional support, and developmental training are important while successful renal transplantation is the ultimate goal for these infants.

\section{Declaration}

All authors have disclosed no conflicts of interest.

\section{References}

1. Geary DF. Attitudes of pediatric nephrologists to management of end-stage renal disease in infants. J Pediatr 1998;133:154-6.

2. Kari JA, Gonzalez C, Ledermann SE, Shaw V, Rees L. Outcome and growth of infants with severe chronic renal failure. Kidney Int 2000;57:1681-7.

3. Ledermann SE, Scanes ME, Fernando ON, Duffy PG, Madden SJ, Trompeter RS. Long-term outcome of peritoneal dialysis in infants. J Pediatr 2000;136:24-9.

4. North American Pediatric Renal Trials and Collaborative Studies (NAPRTCS). 2011 Annual dialysis report. Available from: https://web.emmes.com/study/ped/ annlrept/annualrept2011.pdf. Accessed Nov 2015.

5. Vidal E, Edefonti A, Murer L, et al. Peritoneal dialysis in infants: the experience of the Italian Registry of Paediatric Chronic Dialysis. Nephrol Dial Transplant 2012;27:38895.

6. Shroff R, Rees L, Trompeter R, Hutchinson C, Ledermann S. Long-term outcome of chronic dialysis in children. Pediatr Nephrol 2006;21:257-64.

7. Warady BA, Alexander SR, Hossli S, et al. Peritoneal membrane transport function in children receiving longterm dialysis. J Am Soc Nephrol 1996;7:2385-91.

8. Warady BA, Alexander S, Hossli S, Vonesh E, Geary $D$, Kohaut E. The relationship between intraperitoneal volume and solute transport in pediatric patients. Pediatric Peritoneal Dialysis Study Consortium. J Am Soc Nephrol 1995;5:1935-9.

9. Warady BA, Bakkaloglu S, Newland J, et al. Consensus guidelines for the prevention and treatment of catheterrelated infections and peritonitis in pediatric patients receiving peritoneal dialysis: 2012 update. Perit Dial Int 2012;32 Suppl 2:S32-86.

10. Kidney Disease: Improving Global Outcomes (KDIGO) CKD-MBD Work Group. KDIGO clinical practice guideline for the diagnosis, evaluation, prevention, and treatment of Chronic Kidney Disease-Mineral and Bone Disorder (CKD-MBD). Kidney Int Suppl 2009;113:S1-130.

11. Borzych D, Rees L, Ha IS, et al. The bone and mineral disorder of children undergoing chronic peritoneal dialysis. Kidney Int 2010;78:1295-304.

12. Leung SS, Tse LY, Wong GW, et al. Standards for anthropometric assessment of nutritional status of Hong Kong children. Hong Kong J Paediatr 1995;12:5-15.

13. Rees L. Paediatrics: Infant dialysis-what makes it special? Nat Rev Nephrol 2013;9:15-7.

14. Yap HK, Bagga A, Chiu MC. Pediatric nephrology in Asia. In: Avner ED, Harmon WE, Niaudet P, Yoshikawa N, Emma F, Goldstein SL, editors. Pediatric nephrology. 6th ed. Springer; 2010: 1981-90.

15. Zaritsky J, Warady BA. Peritoneal dialysis in infants and young children. Semin Nephrol 2011;31:213-24.

16. Chiu MC. An update overview on paediatric renal transplantation. Hong Kong J Paediatr 2004;9:74-7.

17. Warady BA, Belden B, Kohaut E. Neurodevelopmental outcome of children initiating peritoneal dialysis in early infancy. Pediatr Nephrol 1999;13:759-65.

18. Lantos JD, Warady BA. The evolving ethics of infant dialysis. Pediatr Nephrol 2013;28:1943-7.

19. Teh JC, Frieling ML, Sienna JL, Geary DF. Attitudes of caregivers to management of end-stage renal disease in infants. Perit Dial Int 2011;31:459-65.

20. Wood EG, Hand M, Briscoe DM, et al. Risk factors for mortality in infants and young children on dialysis. Am J Kidney Dis 2001;37:573-9.

21. Zurowska AM, Fischbach M, Watson AR, Edefonti A, Stefanidis CJ, European Paediatric Dialysis Working Group. Clinical practice recommendations for the care of infants with stage 5 chronic kidney disease (CKD5). Pediatr Nephrol 2013;28:1739-48.

22. Chiu MC, Tong PC, Lai WM, Lau SC. Peritonitis and exitsite infection in pediatric automated peritoneal dialysis. Perit Dial Int 2008;28 Suppl 3:S179-82.

23. Rabindranath KS, Adams J, Ali TZ, Daly C, Vale L, MacLeod AM. Automated vs continuous ambulatory peritoneal dialysis: a systematic review of randomized controlled trials. Nephrol Dial Transplant 2007;22:2991-8.

24. North American Pediatric Renal Transplant Cooperative Study (NAPRTCS). 2005 Annual report. Available from: https://web.emmes.com/study/ped/annlrept/ annlrept2005.pdf. Accessed Nov 2015.

25. Piraino B, Bailie GR, Bernardini J, et al. Peritoneal dialysisrelated infections recommendations: 2005 update. Perit Dial Int 2005;25:107-31.

26. Auron A, Simon S, Andrews W, et al. Prevention of peritonitis in children receiving peritoneal dialysis. Pediatr Nephrol 2007;22:578-85.

27. Rees L, Azocar M, Borzych D, et al. Growth in very young children undergoing chronic peritoneal dialysis. J Am Soc Nephrol 2011;22:2303-12.

28. KDOQI Work Group. KDOQI Clinical Practice Guideline for Nutrition in Children with CKD: 2008 update. Executive summary. Am J Kidney Dis 2009;53:S11-104. 